\title{
Malaysia as global Halal Hub: OIC food manufacturers' perspective
}

\begin{abstract}
Food hubs have received attention from different groups of people who have interests related to food and agriculture. These include the food manufacturers, suppliers, and also small and medium enterprises. Malaysia as a member of the Organization of Islamic Conference (OIC) has aspirations to be the Halal Food Hub for the OIC member countries. This article aims to understand the determinants that influence the OIC food manufacturers' intention to accept Malaysia as a global Halal Hub. Three hundred manufacturers were interviewed and the data were analyzed descriptively through factor analysis. Theory of planned behavior was used to gauge the OIC manufacturers' intention to accept Malaysia as a Halal Hub. The factors affecting the food manufacturers to accept Malaysia as a Halal Hub for the OIC country members are knowledge of Malaysia's intention to become a Halal Hub, confidence in Malaysia, motivation to comply, and the market potential.
\end{abstract}

Keyword: Food manufacturer; Halal Hub; Intention; OIC; TPB 